\title{
ASSESSING THE DISTRACTION POTENTIAL OF CHANGEABLE HIGHWAY MESSAGE SIGNS
}

\author{
Vaughan W. Inman ${ }^{1}$ and Brian H. Philips ${ }^{2}$ \\ ${ }^{1}$ Leidos; ${ }^{2}$ Federal Highway Administration \\ McLean, Virginia, USA \\ 1inmanv@leidos.com; ${ }^{2}$ brian.philips@dot.gov
}

\begin{abstract}
Summary: Two experiments were conducted to assess how changeable message signs (CMS) within the right-of-way affect driver behavior and attention. Experiment 1 evaluated whether repeated exposure to irrelevant messages would cause drivers to fail to respond to a safety critical message. Experiment 2 evaluated whether the presence of a driving irrelevant message designed to attract attention would cause drivers to fail to respond to a hazard in the roadway. In both experiments, drivers completed a lengthy (about $50 \mathrm{~min}$ ) driving simulation in a freeway scenario with CMS every $0.8 \mathrm{~km}(0.5 \mathrm{mi})$. Dependent measures were gaze location, response to safety critical message (Exp. 1), and response to spilled load in roadway (Exp. 2). It was found that (1) when headways were short, drivers tend to focus on the roadway and not on a CMS; (2) repeated exposure to irrelevant messages did not cause drivers to miss safety critical messages; (3) salient CMS images (changing faces) did not cause failures to detect a roadway hazard, and (4) the frequency and duration of looks to salient images and travel time messages were similar.
\end{abstract}

\section{INTRODUCTION}

The experiments reported here assessed the distraction potential of changeable message sign (CMS) displays of non-traffic related content. CMS are used to communicate current information to drivers. Information displayed on these signs may include travel times, incident information, temporary lane restrictions, and alternate route suggestions. Some transportation related public service messages, e.g., "click it or ticket," are also permissible. Because CMS display technology continues to evolve and improve, the potential for the development of novel CMS usages is likely to continue. For instance, some states have requested permission to experiment with sponsorship logos to be displayed when the signs are otherwise unused. Commercial advertising would not be considered for display within the right-of-way. The Federal Highway Administration (FHWA) has requested research to assist future FHWA decision making, and guide validation or update of CMS standards and guidelines contained in the Manual on Uniform Traffic Control Devices for Streets and Highways (Federal Highway Administration, 2009). The current project is intended to serve that role, with an emphasis on guidance to avoid unnecessary driver distraction by CMS content.

In their book on driver distraction, Regan, Lee, and Young (2008) define distraction as "...a diversion of attention away from activities critical for safe driving toward a competing activity." In the experiments described here, two types of safety critical events were simulated and drivers' responses to those events were observed. Where drivers look can also be a clue to where their attention is directed (Corbetta et al., 1998). Although it is possible to attend to locations on which the eyes are not focused, and the level of attention to the location where gaze is fixed can 
vary because of cognitive distraction, the center of gaze is generally a good indication of where drivers are attending (Posner, 1980; Victor, Engström, \& Harbluk, 2008). These experiments used a head-free eye tracker to assess when drivers were looking at a CMS.

The experiments described below examined the distraction potential of information displayed in the right of way by simulating the capabilities of the latest generation of full-color, full-matrix CMS technology.

\section{EXPERIMENT 1}

Two major research questions were examined: (1) whether drivers looked more at signs with frequently changing color images of faces than to blank or travel time signs, which might suggest the salient images distract drivers from their primary task - monitoring the road ahead; and (2) whether drivers exposed to visually salient non-traffic related messages on overhead signs would habituate to, or "lose respect" for, the overhead signs and thus fail to detect a critical instruction to exit the freeway. The relationship between following distance and gaze behavior was also examined.

\section{Experiment 1 Methods}

Participants. Thirty-two individuals, 16 males, completed the study. All were licensed drivers from the Washington, DC metropolitan area. The mean age of participants was 47 years (range 20-85). Twenty-four participants provided interpretable eye tracking data. Otherwise useable data was obtained from eight participants for whom eye tracking was unsuccessful. The mean age of the 24 participants with good eye tracking data was 45 years (range 20-79) and 11 were male. No participant dropped out as a result of simulator sickness.

Driving Simulator. The FHWA's Highway Driving Simulator was used. The simulator consisted of a compact sedan mounted in the midst of a cylindrical screen. The screen consisted of a 240 degree portion of a cylinder with a radius of $2.7 \mathrm{~m}(8.9 \mathrm{ft})$. Directly in front of the driver, the design eye point of the simulator is $3 \mathrm{~m}(9.5 \mathrm{ft})$ from the screen. The stimuli were projected onto the screen by 5 projectors, each with a resolution of 2048 horizontal by 1536 vertical pixels. The simulator's motion base was not enabled in this experiment. The car's instrument panel, steering, brake, and accelerator pedal all functioned in a manner similar to real-world compact cars.

Simulation Scenarios. An eight-lane freeway was simulated. Overhead CMS were located every $0.8 \mathrm{~km}(0.5 \mathrm{mi})$, over a distance of $78.5 \mathrm{~km}$ (48.5 mi). In should be noted that such close spacing of CMS is not without precedent; in the Netherlands speed harmonization CMS are spaced 500 $\mathrm{m}(1640 \mathrm{ft})$ apart, and in the UK minimum active traffic management spacing is considered to be $800 \mathrm{~m} \mathrm{(2600} \mathrm{ft)} \mathrm{(Fuhs,} \mathrm{2010).} \mathrm{One} \mathrm{group} \mathrm{of} \mathrm{participants} \mathrm{was} \mathrm{presented} \mathrm{with} \mathrm{CMS} \mathrm{that} \mathrm{displayed}$ frequently changing faces on every other CMS and travel time messages on the remaining CMS. Another group saw blank CMS instead of faces. The $97^{\text {th }}$ CMS message was the same for all drivers: "ACCIDENT AHEAD/ALL LANES CLOSED/USE NEXT EXIT."

Each CMS spanned all four lanes and approximated the dimensions of a sign $17 \mathrm{~m}(56 \mathrm{ft})$ wide by $2.5 \mathrm{~m}(8.6 \mathrm{ft})$ high. All signs in the simulator were oversized by a factor of 1.75 so that their 
legibility distance approximated real-world legibility distance. A representative faces sign is shown in Figure 1. A representative travel time message is shown in Figure 2.

On faces signs, 34 faces were displayed in a continuously repeating sequence, each for $3 \mathrm{~s}$. Faces were chosen because, it has been shown that human faces attract and hold attention as few other stimuli can (Bindemann, Burton, Hooge, Jenkins, \& de Haan, 2005; Cerf, Frady, \& Koch, 2009). The face stimuli were captured from two sources: non-copyrighted celebrity photographs from the internet and selected faces from the International Affective Picture System (Lang, 2008). The face backgrounds and the location of the faces on the signs both varied.

The travel time estimates descended during the drive and exceeded the end of the scenario by about $30 \mathrm{~min}$.

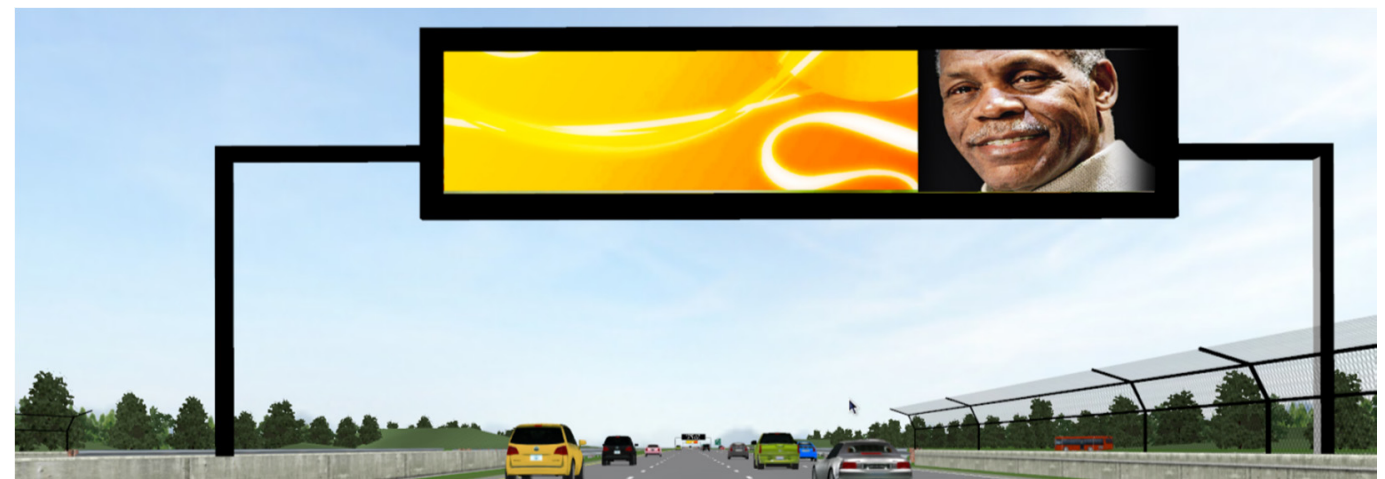

Figure 1. Faces served as salient but driving irrelevant information

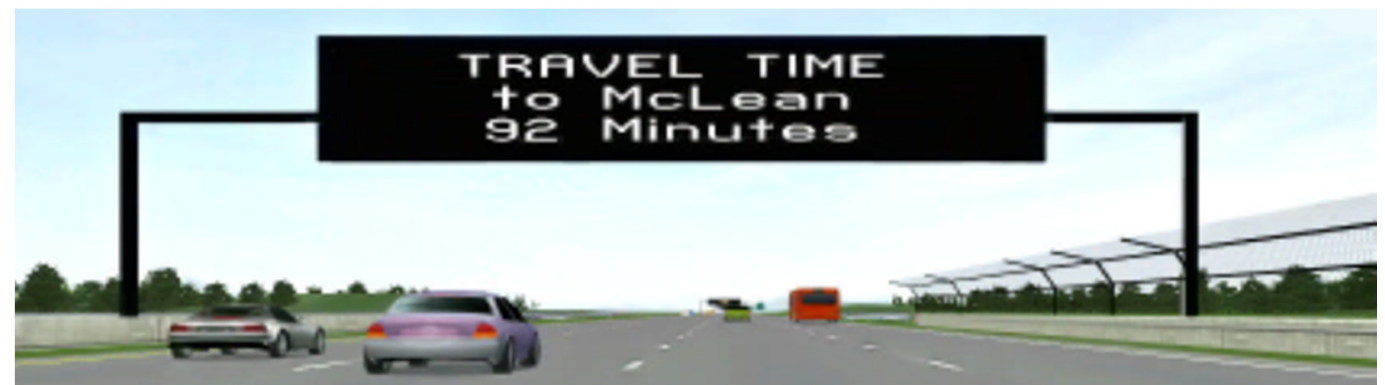

Figure 2. Travel time to McLean was displayed once per mile

Participants were instructed to drive as they normally would, but were encouraged to use the second lane from the right. The posted speed limit was $105 \mathrm{~km} / \mathrm{hr}(65 \mathrm{mi} / \mathrm{hr})$. There was simulated traffic of about 1250 vehicles per hour per lane that maintained speeds that varied around the posted speed, except at designated congestion areas where traffic slowed to around 56 $\mathrm{km} / \mathrm{hr}(35 \mathrm{mi} / \mathrm{hr})$. The 6 congestion areas were $366 \mathrm{~m}(1200 \mathrm{ft})$ in length and separated by $12 \mathrm{~km}$ (7.5 mi). Each congestion area ended $269 \mathrm{~m}(881 \mathrm{ft})$ before a CMS.

In a practice session, a CMS message directed the participant to take a detour at the next off ramp. The detour was intended to make the participants aware that they could use the exit ramps. In the experimental session, exit ramps were present every $2.4 \mathrm{~km}(1.5 \mathrm{mi})$. 
Independent Variables. Whether faces or blank signs appeared on every other CMS was a between group variable. The number of participants in each group was equal (16).

Dependent Measures. In addition to exit taking behavior, three measures of when a participant's gaze vector fell on the CMS were calculated. The least conservative was a glance, which was defined as when the count of the $0.0083 \mathrm{~s}$ gaze vector hits on the CMS exceeded $12(0.1 \mathrm{~s})$. The next most conservative measure was the look, which was defined as any occurrence of 12 or more consecutive gaze vector hits on a CMS. The most conservative measure was the fixation, which was defined as seven consecutive gaze vector hits within a 2 degree (approximate) radius that fell on the CMS.

\section{Experiment 1 Results}

The difference in exit taking between blank and faces groups in response to the take next exit message was not statistically significant by Fisher's Exact Test. These results are shown in Table 1. All participants who took the exit said that they had read the message. Of the nine drivers who failed to exit, seven were asked if they had read the message, and all but one of those seven also claimed that they had read it. The one driver who claimed not to have noticed the warning was in the blank sign group.

Table 1. Response the $97^{\text {th }}$ sign, warning to take next exit

\begin{tabular}{l|lll}
\hline & Failed to Exit & Exited & Total \\
\hline Blank Signs & 4 & 12 & 16 \\
Faces Signs & 5 & 11 & 16 \\
\hline Total & 9 & 23 & 32 \\
\hline
\end{tabular}

Table 2 shows the relationship between glances to the final (warning) CMS and taking the exit for the 24 participants for whom good eye tracking data were obtained. For the final CMS, Table 3 shows means and standard deviations for the various final CMS gaze metrics.

Table 2. Contingency Table Showing Relationship between Glance to Accident Ahead Message and Taking Exit

\begin{tabular}{lcc}
\hline & Glance Recorded & No Glance Recorded \\
\hline Took Exit & 16 & 3 \\
Did Not Take Exit & 4 & 1 \\
\hline
\end{tabular}

Table 3. Mean Counts and Mean Durations for Various Gaze Metrics to Accident Ahead Message

\begin{tabular}{lcc}
\hline & Mean & Standard Deviation \\
\hline Glance Duration & $0.98 \mathrm{~s}$ & $0.98 \mathrm{~s}$ \\
\hline Number of Looks & 4.00 & 4.74 \\
Look Duration & $0.23 \mathrm{~s}$ & $0.30 \mathrm{~s}$ \\
\hline Number of Fixations & 2.58 & 2.47 \\
Fixation Duration & $0.27 \mathrm{~s}$ & $0.29 \mathrm{~s}$ \\
\hline
\end{tabular}

These data suggest that all, or nearly all, participants attended to the warning message, and read it in about 4 looks that totaled about $1 \mathrm{~s}$.

General estimating equations (GEE) models were used to analyze the glance data. There were no 
significant differences in glance durations between faces and travel time signs. Therefore, subsequent glance analyses compared blank CMS to non-blank CMS. The GEE estimate for the probability $\left(P_{e}\right)$ of a glance to a non-blank CMS $\left(P_{e}=0.55\right)$ was significantly greater than the probability of a glance to a blank CMS $\left(P_{e}=0.21\right), \chi^{2}(1)=9.11, p=0.003$.

The effect of car following distance on glance behavior was evaluated. Time gaps were considered short if less than $1.5 \mathrm{~s}$, and long if greater than that amount. Three quarters of all headways were greater than or equal to $1.5 \mathrm{~s}$. Participants had a significantly higher probability of glancing toward a CMS when their headway was long $\left(P_{e}=0.490\right)$ than when short $\left(P_{e}=\right.$ $0.380), \chi^{2}(1)=4.07, p=0.044$.

\section{Experiment 1 Discussion}

CMS with changing displays of faces did not attract more visual attention than travel time messages. Irrelevant messages on 96 CMS over 45 minutes of driving did not cause drivers to ignore a safety critical warning message on the $97^{\text {th }} \mathrm{CMS}$. Drivers regulated their attention to CMS with traffic conditions and were less likely to glance at CMS messages when their headway was short.

\section{EXPERIMENT 2}

Experiment 2 examined whether the content on a CMS would make it more likely that drivers would miss a roadway hazard; here a spilt load of logs $91 \mathrm{~m}(300 \mathrm{ft})$ upstream of a CMS, which is illustrated in Figure 3. The logs were placed based on the Experiment 1 finding that the mean distance from the CMS of the last CMS glance was between $146 \mathrm{~m}(480 \mathrm{ft})$ and $67 \mathrm{~m}(220 \mathrm{ft})$. Thus, the logs were positioned to become visible at a distance when glances to the CMS were most likely.

\section{Experiment 2 Method}

Participants. Complete data, which included interpretable eye tracking, were obtained from 73 participants. Eighty participants (51 males) completed the drive and provided behavioral performance data. The median age of the participants who completed the drive was 33.5 years (range 18 to 73 ).

Simulation Scenario. The same driving simulator and eye tracking system from Experiment 1 were used. All participants were presented with all three CMS content types, with every third sign having blank, travel time, or faces displayed. The simulated freeway was the same as that described previously except that the drive was reduced to $59.5 \mathrm{~km}(37 \mathrm{mi})$ and $72 \mathrm{CMS}$. There were two between-group conditions: (1) which message content was displayed on the CMS just beyond the spilled load, and (2) whether the spilled load preceded the $4^{\text {th }}$ CMS (Early) or $72^{\text {nd }}$ CMS (Late).

Instructions to the participants were the same as in Experiment 1. The speed of the simulated traffic was increased so all traffic traveled more than $106 \mathrm{~km} / \mathrm{h}(66 \mathrm{mi} / \mathrm{h})$. Traffic speed was increased to decrease the desire to change lanes, because the spilled load was in the lane 
participants were asked to use.

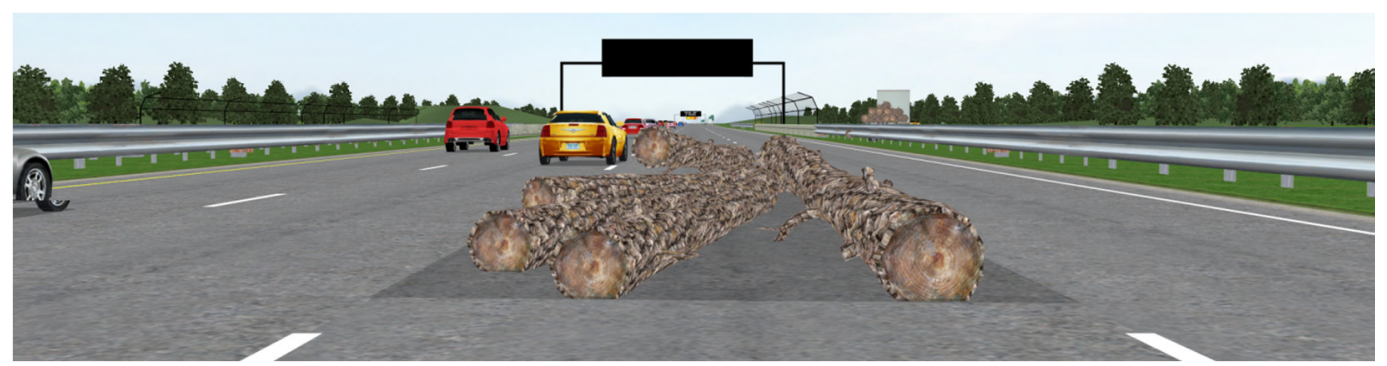

Figure 3. Driver's view (cropped) of spilled load from 39 m (128 ft)

\section{Experiment 2 Results}

The spilled load presented a challenging task; 26 percent of drivers hit the logs. However, the message content on the CMS immediately beyond the logs had no significant effect on log strikes. The location of the logs also did not have a significant effect. Table 4 shows hazard avoidance frequency as a function of CMS content and spill location.

Table 4. Number of participants who hit or avoided spilled load shown as a function of load location and dynamic message sign content

\begin{tabular}{|c|c|c|c|c|}
\hline & Blank & Travel Time & Face & Total \\
\hline \multicolumn{5}{|l|}{ Early } \\
\hline Avoided & 5 & 11 & 8 & 24 \\
\hline Hit & 7 & 2 & 4 & 13 \\
\hline Total & 12 & 13 & 12 & 37 \\
\hline \multicolumn{5}{|l|}{ Late } \\
\hline Avoided & 12 & 12 & 11 & 35 \\
\hline Hit & 3 & 3 & 2 & 8 \\
\hline Total & 15 & 15 & 13 & 43 \\
\hline
\end{tabular}

Headway was not a factor in this experiment. As in the previous experiment, the sign content effect was significant, $\chi^{2}(2)=41.06, p<.001$. The expected probability of a glance to a faces and travel time message was 0.55 , whereas the expected probability of a glance to a blank CMS was 0.27 . Sign content significantly predicted fixation duration, $\chi^{2}(2)=15.10, p=0.001$. Posthoc comparisons indicated mean fixations on travel time signs $(520 \mathrm{~ms})$ were significantly longer than those to blank $(390 \mathrm{~ms})$ or faces $(450 \mathrm{~ms})$ signs, the latter two of which were not different from each other.

\section{Experiment 2 Discussion}

The spilled load presented a challenge to participants, which resulted in just over one-quarter of the participants colliding with the obstruction. However, the type of content on the CMS did not affect the probability of striking the logs, suggesting that CMS content, regardless of type, does not distract drivers from their primary task of monitoring the roadway. Although it is plausible that CMS content could be designed to deliberately distract drivers, perhaps by displaying emotionally disturbing graphics, our attempt to distract them with faces that changed every $3 \mathrm{~s}$ was not sufficient to cause a measureable increase in distraction. 


\section{CONCLUSION}

Frequently recurring driving irrelevant, yet salient, CMS messages did not appear to cause drivers to habituate to, or lose respect for, safety critical messages with the right of way. Nor did these messages appear to detract from detection of a roadway hazard. In addition, the frequency and duration of looks to salient images and travel time messages were similar. It is possible that exposure over many trips might cause habituation, or that irrelevant messages that could only be recognized as such after being completely read (such as advertising made to look like a traffic related message) might cause distraction. The critical message at the end of Experiment 1 was noticed by all but one participant, even though not all the participants who responded to the message fixated on the sign. The large letter messages on modern CMS are perceivable with near peripheral vision.

\section{ACKNOWLEDGMENTS}

This research was sponsored by the FHWA Office of Operations under contract DTFH61-08-C00006, with guidance from Kevin Sylvester of the MUTCD Team.

\section{REFERENCES}

Federal Highway Administration. (2009). Manual on Uniform Traffic Control Devices for Streets and Highways 2009 Edition, Including Revision 1 and Revision 2. Retrieved June 17, 2014, from http://mutcd.fhwa.dot.gov/pdfs/2009/mutcd2009edition.pdf

Regan, M. A., Lee, J. D., \& Young, K. L. (2008). Chapter 1. Introduction. In M. A. Regan, J. D. Lee \& K. L. Young (Eds.), Driver Distraction: Theory, Effects, and Mitigation (pp. 3-7): CRC Press.

Corbetta, M., Akbudak, E., Conturo, T., Snyder, A., Ollinger, J., Drury, H., . . Shulman, G. (1998). A Common Network of Functional Areas for Attention and Eye Movements. Neuron, 21(4), 761-773.

Posner, M. I. (1980). Orienting of Attention. The Quarterly Journal of Experimental Psychology, 32(1), 3-25. doi: 10.1080/00335558008248231

Victor, T. W., Engström, J., \& Harbluk, J. L. (2008). Distraction Assessment Methods Based on Visual Behavior and Event Detection. In M. A. Regan, J. D. Lee \& K. Young (Eds.), Driver Distraction (pp. 135-165): CRC Press.

Fuhs, C. (2010). Synthesis of Active Traffic Management Experiences in Europe and the United States (pp. 35p). Washington, DC: Federal Highway Administration.

Bindemann, M., Burton, A. M., Hooge, I. T., Jenkins, R., \& de Haan, E. H. (2005). Faces Retain Attention. Psychon Bull Rev, 12(6), 1048-1053.

Cerf, M., Frady, E. P., \& Koch, C. (2009). Faces and Text Attract Gaze Independent of the Task: Experimental Data and Computer Model. Journal of Vision, 9(12), 10 11-15. doi: $10.1167 / 9.12 .10$

Lang, P. J., Bradley, M. M., Cuthbert, B. N. (2008). International Affective Picture System (IAPS) Retrieved 12/06/2012, 2012, from http://csea.phhp.ufl.edu/media.html\#topmedia 